\section{Clinital Commentaties}

ox

\section{CERTAIN RARE FORMS OF DISEASE CONNECTED WITH SYPHILIS.}

Delivered at the London Hospital.

BY

JONATHAN HUTCHINSON, F.R.C.S.,

SURGEON TO THE HOSPITAL, AND LECTURER ON SURGERY AT THE MEDICAL SCHOOL.

Gentlemen, -I sometimes feel almost annoyed at being compelled so very frequently to prescribe iodide of potassium. We go from bed to bed, and to cases apparently of the most different kind, and for almost one in every three I am obliged to dictate the same prescription.* Iodide of potassium in large doses, generally in combination with ammonia, and sometimes with the bichloride of mercury, seems to be the panacea for almost a majority of our cases of chronic disease. Here is a man with convergent squint and double vision : he has come up from Cornwall to be treated, and he looks perfectly healthy. We investigate his case, and pronounce the diagnosis of syphilitic paralysis of his right sixth nerve. A man, a few beds lower down, came in on account of a pain in his heel, which had resisted all treatment for months, and prevented him from either working in the day or sleeping at night. $\mathrm{He}$, too, looked quite healthy; but, on probing his symptoms and history, I gave a syphilitic diagnosis, and, what is more, confirmed it by quickly curing him. A woman was admitted six weeks ago with numerous large ulcers on the legs, and some also on her arms. She had scars of former ulcers about her knees; and the multiplicity of the sores and the worm-eaten character of their edges confirmed the suspicion formed at first glance. She, like the former patient, had had much previous treatment without result, and got well most rapidly under our favourite prescription. There is a boy in Talbot Ward with ascites, and with a liver which reaches below his navel, and with hard periosteal nodes on almost every long bone in his body. His sister was also here not long ago, suffering from nodes; and his mother I have repeatedly had under care during the last fifteen years, for various forms of constitutional syphilis. We have also in the same ward two men suffering from chronic enlargement of the testis, which we attribute to the same almost ubiquitous taint. One of them is already nearly well; and the other, I have no doubt, will soon be so.

If we go down stairs to the women's ward, we shall find some most interesting cases. 'There is Mrs. G., the unfortunate wife of a very dissolute seacaptain. She came into the hospital in order to have her sight improved by an artificial pupil, in consequence of adhesions, etc. One of her eyes is shrunk,

* In mentioning this proportion, I of course allude only to our wards for chronic disease, and do not include those for accidents. soft, and collapsed; and she has, or rather had, the pupil of the other eye almost wholly closed by lymph. I have made her an artificial pupil, and she sees as much better as we could expect. You will notice that she speaks thickly; uses her limbs awkwardly; and, although not yet even middle-aged, looks as if she were entering on second childhood. Her history is that of a case of subacute syphilitic inflammation of the pia mater. She first came under my observation more than a year ago, at the Moorfields Hospital, for most acute double iritis, and covered with syphilitic rash. The pupils were already closed with lymph, and she was already salivated. We adopted the treatment which seemed best; but, as you see, only with very partial results as regards her eyesight. In her right eye, choroiditis and inflammation of the vitreous body afterwards set in; and the eye ultimately became soft, and then shrunken, as it now is. After this, she became exceedingly nervous, could not sleep at nights, and was at length laid up at home with delirium. She was now for some weeks under private care with a form of mania; all her limbs became weak and tremulous; and, when she recovered, those of her left side were weaker than the others. As syphilitic inflammation often attacks the choroid coat of the eye, there is no reason why it should not affect the vascular membrane of the brain ; and to suppose that it did so in this instance would well account for all her symptoms.

In the same ward is a girl aged 15 , whom we admitted a week ago with large, ragged-edged, very deep ulcers on the back of one leg. 'They are ulcers of a character which, if seen in an adult, you would at once pronounce to be those of tertiary syphilis. And, in confirmation of that view, she has an induration in front of one tibia. 'The girl is, however, only fifteen ; and she has had these ulcers for several years. The disease in her is congenital; and she shows, in order to help us to this opinion, one of the most typical sets of teeth that I have ever seen. You will note that her physiognomy would not have led us to suspect her, for there is nothing very peculiar in it. The bridge of her nose is not flattened; her forehead is not protuberant; nor are there any scars of fissures about her mouth. Her teeth, however, tell the tale, and are so characteristically malformed that I should venture a positive opinion without other evidence. You will watch the effect of specific treatment upon her ulcers. I will ask you to observe that the ulcers are clearly not due to mere ordinary cachexia, for the girl looks healthy; and, should they be well under iodide of potassium in a few weeks, I shall then ask you to remember that they had existed for several years before she came here.

I have only mentioned about a third of the curious forms of constitutional syphilis at present under our care. You will observe that I omit all primary and secondary forms of disease. Those which we shall at present consider are such only as occur at long periods after the original disease, and come into the category of late tertiary affections. Our knowledge of this latter class has of late years very much improved, and we are now able to recognise many as such which formerly we did not know; and, I am glad to add, we are able to exclude some from suspi cion which were formerly much suspected.

'The feeling of annoyance to which I adverted, as sometimes arising when one is obliged over and over again to prescribe the same specific, has its origin in 
a doubt and a fear-a doubt of one's own accuracy of judgment; and, secondly, a fear of the criticisms of others. A sort of fear arises as to whether, after all, the suggestions now and then made, "Oh, he is riding his hobby - he sees syphilis in everything," may not have some foundation in truth. Now, this self-mistrust is very natural and very useful in its proper place, but let me warn you not to let it go too far ; and, as regards the criticisms of others, let me beg you not to allow them to influence your judgment one iota. There is not the shadow of a doubt that the syphilitic virus is capable of producing effects at extremely remote periods, and after long intervals of apparently good health. There is not the least doubt, further, that this virus is very widely diffused amongst all classes of the community. We must, therefore, expect to encounter its results very frequently, and under very varied circumstances. Our duty in this matter is to find out with accuracy, amongst the great variety of chronic maladies which come before us, which are syphilitic and which are not. Upon our success in diagnosis will depend our success in treatment. 'There is no room for joking scepticism. It is a simple question of fact. My patient presents a form of disease which we know must have had some cause. We know, further, that the syphilitic taint is a cause quite capable, in some instances, of producing a similar result; and we want to find out by collateral evidence whether that cause is in operation here. And, if it should so turn out that we are obliged, after painstaking investigation, to believe in the presence and efficiency of that special cause in five out of every twenty patients, it cannot be helped. We want truth; and, if that is the truth, we must take it and act on it. A good means of checking our own conclusions is always at hand. I allude to the results of treatment. In most cases of tertiary syphilis, the consequence of acquired disease, the effects of specific treatment are most prompt and definite. Unfortunately, it is not so in a few, especially in those which concern the nervous system; and it is not so in many which are consequent on inherited taint. In these, the efficacy of specific treatment is often but ill marked.

Before proceeding to relate cases in detail, there are three or four doctrines regarding syphilis which have of late years fought their way to general belief, to which I must ask your especial attention.

The first of these is, that tertiary syphilis may, and often does, last through a person's life. By tertiary syphilis we mean all forms of specific disease occurring subsequently to the primary and exanthematic stages ; practically, everything that comes later than two years after the infecting sore. The exanthematic stage usually occurs within two months of the original sore, and is rarely protracted beyond the year. We will, however, to give good margin, say two years. After this, the disease appears to have no stages; periods of entire latency, of the most variable lengths, may occur. The symptoms which show themselves are irregular, and subject to repeated relapses after cure by treatment. Between the secondary and tertiary symptoms, an interval of health, often of several years, and it may be of many, supervenes.

The second cardinal doctrine, as regards tertiary disease, is what $I$ have just adverted to : that it may be latent. By latent, I mean that it may be entirely concealed. The patient may appear to be in robust health ; may not show the slightest trace of a symptom; may even marry and beget healthy children ; and yet the disease may reappear. In a recent lecture, I brought forward a case in which the period of latency had been twenty years; and I shall have to mention several others, in which it has been nearly as long. The phenomena of latency are even more wonderful in respect to inherited than they are in regard to acquired disease.

Thirdly, I wish to insist that it is very common for married women to acquire a constitutional taint, without having ever had primary or secondary disease, and, therefore, without either themselves or their husbands having the slightest suspicion as to what has happened. This occurs in women who have borne children to syphilitic husbands, and who have imbibed from the fluids of the foetus the poisonous material. We will call this "Syphilis by conception".

Lastly, we must remark, that it is very possible for a patient to have primary syphilis, and never be aware of it. In a woman, this may easily be. A small indurated chancre causes very little irritation, and is perhaps never suspected to be of any consequence. It so happens, that the sore most likely to infect gives the least local annoyance; and many an inexperienced man will allow a sore of this kind to go on without treatment, and afterwards, in good faith, assure his surgeon that he has " never had a chancre". But there are cases even yet more difficult to explain, in which even a practised eye never finds the infecting sore. I have more than once or twice known it to happen, that surgeons or medical students, who came under treatment for secondary forms of disease, and who made not the slightest attempt at secresy, assured me that they had never been aware that they had primary sores.

'The chief lesson to be drawn from these various sources of fallacy in the histories we receive is, that the surgeon must learn, by widely extended practice, to trust to his own eyes for a diagnosis. The importance of being independent of what our patients may tell us can scarcely be exaggerated in this matter. Not only will it save us from being misled by erroneous statements, but it will in some cases save the necessity for asking annoying and painful questions.

We will now proceed with some clinical illustrations of our remarks.

Latent Syphilis. An Interval of Eight Years without Symptoms, the Patient enjoying Robust Health. Ulcerative Destruction of the Palate, with Psoriasis of the Backs of the Hands. Wendon Dawson, aged 30, a dark complexioned man, looking much older.

Nine years ago, he had a sore. He was then in the navy ; went into Chatham Hospital ; " took mercury pills, and was salivated freely." He had a bubo in one groin, which suppurated and remained open for two. months. He left the hospital after six weeks, and took no more medicine. He recollects that he had a sore-throat; but does not remember any rash.

On leaving the hospital, he went on board ship again; and had good health and remained quite well. Three years later, he married. His wife has never conceived, and has remained in perfect health. Very soon after he married, he had "yellow jaundice," and was very ill for a week or more; he was at home a month.

About a year ago, his throat began to be sore; and 
six months after this, sore patches shewed themselves on the backs of his hands. He has only been under treatment for these affections for about two months. During the interval since his discharge from the Chatham Hospital, with the exception of the attack of jaundice, he has enjoyed good health; and has been wholly free from symptoms; " never lost a single day's work." We questioned him most closely, and could not make out that he had had any suspicious symptoms whatever.

January 13th, 1864. The subject of the above notes was sent to me by Mr. Swales of Sheerness. He is now cachetic, and speaks in a hoarse whisper. His soft palate is extensively destroyed by ulceration, which is still spreading; his breath has the fotor of diseased bone. The backs of his hands and wrists are covered by patches of psoriasis, with fissures and peeling of epidermis, just like the common psoriasis palmaris. There is not a single patch in either palm. There are two or three similar patches on each cheek.

The man states that he has never had any venereal disease since the one described nine years ago, and there is not the least reason to doubt his statement. Let us note, also, that, although salivated in the first instance, he has never needed any medicine since, except during the last few months.

Under about two months' treatment, this patient got quite well as regards his throat; and his psoriasis, although not cured, was much benefited.

In the next case, we have again phagedæna of the throat; but its chief interest attaches to the fact that the man has entirely lost his hearing. With regard to the throat. I may, however, here ask your attention to the difference between the secondary and tertiary forms of disease as they occur in it. In the secondary stage, the inflammation is always superficial, and always ends in cicatrisation, without noticeable loss. Indeed, excepting in the tonsil itself, there is rarely any ulceration. On the velum palati and pharynx, it is rather inflammatory swelling than ulceration. All the deeply ulcerative or phagedænic affections of the throat occur years after the primary disease, and are tertiary. Of this, both the cases before us are examples.

Case of Syphilitic Cerebral Deafness. We have, in a man now in Talbot Ward, an interesting example of deafness in connection with constitutional syphilis. The man is utterly deaf, so that we have to communicate with him by writing. He was admitted a few weeks ago for syphilitic ulceration of the soft palate, which, under the influence of iodide of potassium, is rapidly getting well.

His history is briefly this. He had chancres six years ago, and again three years ago; on the latter occasion, with suppurated buboes. He has been salivated for various symptoms two or three times. About twenty months ago, his hearing began to fail, and he had singing noises in his ears. There was no pain in his ears, nor any discharge from them. $\mathrm{He}$ had, however, a good deal of pain in his head. In the course of a month from the beginning, he tells us, that he had got as deaf as he is now. Mark the very rapid progress of the affection. Both ears were involved from the beginning; but one more than the other; indeed, he still pretends to be able to hear a little in one, though which it is might puzzle you to find out. He had no sore-throat at the time. He was salivated on account of the deafness; but it did him no good. Nearly a year later, he had a severe illness, of which some of the chief symptoms were giddiness and great pain in his head. He had, also, swellings in his scalp. Double vision, with dilatation of the pupil of the right eye, followed (paresis of right third nerve). For this he was again salivated, and his eye, or rather his third nerve, quite recovered. Lastly, about three months ago, he was attacked with syphilitic phagedæna of the velum palati, for the remains of which he now comes under our care. You may observe that the velum is very extensively destroyed; but it is now rapidly healing. In other respects, he seems tolerably well; but his complexion is pale and earthy.

It is a point of great interest and importance to determine, if we can, upon what his deafness depends. Although diseases of the eye, leading to greater or less of damage to the function of sight, are common enough in syphilis, yet with the ear it is quite different. Cases like the present are, I believe, exceedingly rare. Now, in respect to the organ of sight, we have syphilitic disease of very different parts. Inflammation of the iris is the most common; next to it come inflammations of the choroid and retina; and, lastly, disease either of the optic nerves themselves, or of the centres from which they arise in the brain. The former may greatly damage the function, but they rarely quite destroy it; the latter not unfrequently lead to complete blindness. 'The fact that the poor fellow before us is almost absolutely deaf, is sufficient, therefore, in itself, to excite a suspicion that his disease involves either the nerve-trunks or the nerve-centres. If it depended upon disease of the tympanum or external ear, or even of the internal ear itself, it is improbable that it would be complete on both sides. 'The speculum, also, gives us great help ; for it shows us that, in each of our patient's ears, the membrana tympani is not in the least damaged. 'The external ear is, on each side, remarkably clean ; not a vestige of wax or of epidermic accumulation obstructs our view, and the dry bluishwhite membrana tympani, with the handle of the malleus attached, can be inspected without the slightest difficulty. His history quite fits with this state of things; for he never had either pain or discharge from the ears. It is possible that there might be some obstruction of the Eustachian tubes; but this is improbable, since it would not explain utter and symmetrical deafness; and we have the fact, that his throat did not begin to be sore till long after the loss of hearing.

Thus, then, we are brought, by the method of exclusion, to our original conjecture, that the nerve of hearing must be the part damaged. Now, it is possible that the auditory nerve might be pressed upon by effusion from the periosteum in the auditory canal ; but this hypothesis, in the present instance, I reject, for two reasons: first, that the disorder is so symmetrical; and, secondly, that if the portio mollis were so compressed, the portio dura would, in all probability, suffer likewise; whereas, as you see, it has wholly escaped. My belief is, therefore, that the real cause of the lesion is syphilitic disease of those portions of the brain, medulla oblongata, and cerebellum, from which the auditory nerve arises. It is probably analogous to amaurosis, with white atrophy of the optic nerves, consequent on changes in the corpora quadrigemina. Iou will note that other symptoms from which the man has suffered favour this opinion. IIe has had a prolonged illness, attended by giddiness; and he has suffered much from pain in his head and noises in his ears. He has even had 
paralysis of a special nerve (right third), from which he has recovered.

Now, although syphilitic deafness from cerebral disease is very rare in the acquired form of the disease, it is far from being so in that which is inherited. In my little work on Syphilitic Diseases of the Eye and $E a r$, I have described a form of deafness almost the exact counterpart of that from which our present patient has suffered; and ending, as in him, after a short course, in utter extinction of the special sense. Of this I have adduced numerous instances; but all were in the subjects of inherited syphilis. I had not then seen a single well-marked example in acquired syphilis. A similar remark mar be made in reference to cerebral amaurosis, which we not very unfrequently meet with in the subjects of inherited disease, but only rarely in those who have acquired the taint de novo..

It may, perhaps, not be without its interest, if I read to you the notes of the last case $I$ have seen of syphilitic cerebral amaurosis. It was one of the best marked that I have ever had an opportunity of investigating. You will notice some points of close analogy between what we may designate syphilitic cerebral deafness and syphilitic cerebral blindness. In both the progress is rapid and usually symmetrical, and in both the extinction of function is mostly complete. In both, a few other slight cerebral symptoms are usually present, such as ringing in the ears, giddiness, etc. ; and in both, there is a remarkable absence of any symptoms referable to the external organ of the special sense. Let me add, that both are most intractable under treatment. You will notice that each of our patients had been salivated, the one for impending blindness due to inherited syphilis, the other for impending deafness due to acquired syphilis; and in neither did this measure retard the course of the disease. I have witnessed a similar failure in many other cases; cases, too, in which there was no doubt whaterer as to the diagnosis. Iodide of potassium, in these affections, is a far more reliable remedy than is mercury.

Professional Indiscretion. Owing to the appearance of a most injudicious and ill-advised paragraph in the Kentish Gazette, an inquest was held on the body of Thomas Bedwell, a labourer, living at St. Dunstan's, who died somewhat suddenly, while under the care of $\mathrm{Mr}$. Rigden. It appears that the poor man was subject to epileptic fits, for which Mr. Rigden treated him. He had seen the man on Sunday morning, and sent him some medicine. In the afternoon he became worse; and, Mr. Rigden being away from home, Mr. A. B. Andrews was called in. From some utterly inexplicablecause, this gentleman thought fit to hand over the medicine supplied by $\mathbf{M r}$. Rigden to the care of the police; and hence arose a rumour to which our cotemporary, with a most reprehensible want of caution, gave circulation that Mr. Rigden had administered to the patient opium in such a manner as to cause his death. At an inquest held to clear up the affair, it was shown that the rumours were completely groundless. Mr. Andrews himself stated at the inquest that the deceased had " had three epileptic fits in his presence, which fits were the cause of his death." The coroner said, that but for the paragraph in the newspaper no inquest would have been necessary. The evidence was very plain, and Mr. Rigden was entirely clear of all blame. (Kent Paper.)

\section{Illurstrations \\ or}

\section{HOSPITAL PRACTICE: METROPOLITAN AND PROVINOIAT.}

\section{ST. MARY'S HOSPITAL.}

CLINICAL REPORTS ON THE PAPULAR DISEASES OF THE SKIN.

By Georae Nayler, F.R.C.S., Assistant-Surgeon to the Royal Orthopædic Hospital; Pathological Curator of the Museum of St. Mary's Medical School.

[Continued from page 583 of last volume.]

Lichen Prlaris, so called from its involving the hairs which pierce the papules in their centre, is a rare variety. The hair-follicle becomes filled with epithelium and its débris; and a number of small acuminated papulæ are observed in place of the papillæ, having each on its apex a single hair. It is chiefly developed on those parts which are covered with soft fine hair, as the neck or chest. I had the opportunity of seeing, some months ago, a remarkable instance of this kind among the out-patients in Mr. Startin's practice, in a boy, where the disease was mostly seen on the back of the neck, and appeared not unlike the small rough eminences on the surface of an echinus. In this case, the loins and shoulders were also covered with lichen in its ordinary form.

lichen lividus, like the preceding, is also uncommon. Mr. Startin has noticed its occurrence about once in 1800 cases; and Rayer relates having only seen it twice. It is almost always united with brokendown or feeble health, and is generally seated on the extremities. The spots are of a purple colour, intermingled with petechiæ.

J. G. (No. 99,449), aged 52 years, applied for relief, on October 13th, 1862, at the Skin Hospital, with the eruption chiefly seen on the inner side of the legs. It was like a number of purple dots, each of an average diameter of a pea ; some were distinct, others more or less fused. To the hand, the surface appeared slightly raised. $\mathrm{He}$ was in delicate health, and complained of the least exertion being attended with fatigue. When in bed, the spots assumed a brighter colour, and occasioned some degree of irritation. For several years, he had been subject to rheumatism. He was ordered to take a mixture of steel with colchicum twice a day, and to sponge the parts with a mixture of nitric acid lotion and red lotion (two ounces of each, with eight ounces of water). (The first of these contains half a drachm of dilute nitric acid to an ounce of water; and the second, two grains of the bichloride and one of the bisulphuret of mercury to an ounce of water.) He rapidly improved under this treatment; and on the 1st of November he was nearly well. Anxious to know how he was getting on, I heard from him some months afterwards, when he informed me that he since had another slight attack, from getting wet through. He then took the same remedies, and soon recovered.

Lichen circumscriptus is the name given to the disease when it forms a circumscribed patch, having a defined border, or is represented by several small patches. It is not unfrequent on the hands, or the popliteal space, or the nape of the neck. Its colour is of a dark red. In some instances, it is prolonged 